\title{
Effect of Aerobic Training on Selected Cardiopulmonary Parameters in Myocardial Infarction Patients with Stroke
}

\author{
Zeezy Soliman Eraky, Nesreen Ghareb El-Nahas, Naguib Mohamed Salem ${ }^{3}$, \\ Samir Abdelfattah El-gazar ${ }^{4}$, Ahmed Ali ${ }^{5}$ \\ ${ }^{1}$ Assistant Lecturer, Faculty of Physical Therapy, Modern University for Technology and Information, ${ }^{2}$ Professor \\ of Physical Therapy for Cardiovascular, Respiratory Disorder and Geriatrics, Faculty of Physical Therapy, Cairo \\ university, ${ }^{3}$ Dean of Faculty of Physical Therapy, Modern University for Technology and Information, ${ }^{4}$ Dean of \\ Faculty of Physical Therapy, Heliopolis University, ${ }^{5}$ Lecturer in Department of Neurology Faculty of Medicine, \\ Beni Suef university
}

\begin{abstract}
Background: Patients in cardiac rehabilitation are typically advised to complete a period of maintenance phase. The purpose of this study was to determine if there was any difference in effect of aerobic training on selected cardiopulmonary parameters in myocardial infarction patients with stroke. Methodology: Forty patients of both sexes with age 40-50 years with chronic myocardial infarction patients with stroke after 6 months participated in the study. Patient's were assigned for 4 weeks into two groups: group (A) received aerobic training and traditional physical therapy program and group (B) which received traditional physical therapy program. Patients were assessed pre and post treatment using through Stress exercise test unit (Modified Bruce protocol) and modified ashwarth scale. Results: This study revealed that there is significantly improved in resting heart rate $(10.10 \%)$, maximum heart rate $(4.67 \%)$, METs $(64.95 \%)$, maximum systolic blood pressure (4.45\%), maximum diastolic blood pressure $(9.45 \%)$ and VO2 max (35.36\%) variables in group (A) treated by aerobic training than those of traditional physical therapy program only. Conclusion: Aerobic training was a valuable method for management myocardial infarction patients with stroke.
\end{abstract}

Key Words: Myocardial Infarction, Stroke, Aerobic Training, Cardiopulmonary Parameter)

\section{Introduction}

Myocardial Infarction is defined by Borja Ibanez et $\mathbf{a l ,}{ }^{(\mathbf{1})}$ as myocardial cell necrosis due to significant and sustained ischaemia. It is an acute manifestation of atherosclerosis-related coronary heart disease. Myocardial Infarction results from either coronary heart disease, which implies obstruction to blood flow due to plaques in the coronary arteries or, much less frequently, to other obstructing mechanisms.

Individuals after stroke generally have low endurance for exercise as a secondary consequence of immobility. The VO2max values are $25-45 \%$ lower than in age-matched, healthy patients. This early and persistent decline in aerobic capacity can delay or inhibit participation in a therapeutic exercise program, complicate the rehabilitation process and long-term post-stroke course of care, and limit the ability of the individual to perform functional activities independently.
(2)

A cardiopulmonary exercise test compares the coronary circulation during physical exertion, showing any abnormal blood flow to the myocardium (heart muscle tissue). The results can be interpreted as a reflection on the general physical condition of the tested patient. This test is used to diagnose coronary artery disease and used as prediction after a myocardial infarction ${ }^{(3)}$.

Aerobic exercise (also known as cardio) is physical exercise of low to high intensity that depends primarily on the aerobic energy-generating process. Aerobic literally means "relating to, involving, or requiring free oxygen", and refers to the use of oxygen to adequately meet energy demands during exercise via aerobic metabolism. Generally, light-to-moderate intensity activities that are sufficiently supported by aerobic metabolism can be performed for extended periods of 


\section{I) Evaluation procedure}

\section{Material and Method}

Patient Selection

Forty patients of both sexes (31 men and 9 women) with age 40-50 years was participated in the study, the study was delimited to chronic myocardial infarction patients with stroke after 6 months. They were selected from Physical Therapy Center, Modern University for Technology and Information.

\section{Inclusion Criteria}

Patients who demonstrate a mild spasticity according to Modified Ashwarth scale and Patients able to walk independently.

\section{Exclusion Criteria}

Patients having contraindication for stress test, Musculoskeletal or neurological disease that may affect walking, patients who didn't follow instructions (Aphasia, blindness and deafness) and Patients who had marked sensory loss.

Group (A): consist of twenty stroke patients (16 men and 4 women) received aerobic exercise (treadmill training) and traditional physical therapy program.

Group (B): consist of twenty stroke patients (15 men and 5 women) received traditional physical therapy program.

Instrumentation:

Instrumentation:

Assessment equipment

\section{Stress exercise test unit.}

QUARK_CPET, COSMED with 12 channels ECG to measure resting heart rate, maximum heart rate, METs, maximum systolic and diastolic blood pressure and $\mathrm{VO} 2$ max.

\section{Methodology}

Steps of evaluation carried at baseline of the study for both groups and re-assumed after 4 weeks of training.
Stress test

Patient instructed not to eat at least 2 to 3 hours before the test. Patient was asked about the drug being taken, and potential electrolyte level abnormalities. A 12-lead ECG was applied in standing position. Careful explanations of the test; the testing procedure. The optimal exercise protocol (Modified Bruce protocol) last 10 minutes and will be adjusted to the patients. Begin exercise test, monitoring the 12 lead ECG, vital signs, oxygen saturation, and symptoms throughout the test. At regular intervals, asking patients how about Chest or arm discomfort, Short of breath, Dizzy, Lightheaded or Any other unusual symptoms. When the test starts there is half minute before the treadmill start then the phase of warming up for 2 minutes with speed $1.4 \mathrm{mph}$ and 0 in inclination then exercise phase for 8 minutes with speed $2 \mathrm{mph}$ and 0 inclination and final cooling down for 2 minutes with speed $1.4 \mathrm{mph}$ and 0 inclination. After the test end wait until symptoms and/or ECG and vital signs returns to baseline.

\section{Modified Ashwarth scale (MAS):}

The MAS was done in supine position. Because spasticity is "velocity dependent", the MAS were done moving the limb at the "speed of gravity." The test was done for the maximum of three times for each joint. If it is done more than three times the short-term effect of a stretch impacts the score;

II) Treatment Procedure:

\section{A) Group A:}

Patients received 4 weeks of aerobic training and traditional physical therapy, three times per week for 45 minutes per session.

Patients obtained aerobic training (treadmill training) through speed range from 0.6 to $1.3 \mathrm{KM} / \mathrm{H}$, $0^{\circ}$ incline and no resistance.

Traditional exercise program for both groups:

Relaxation technique for spastic muscles, Facilitatory technique for antispastic muscles, stretching exercise to prevent shortening, Proprioceptive Neuromuscular Facilitation (PNF) and Trunk control training. 


\section{B) Group B:}

Patients received the same traditional physical therapy training for 4 weeks as in group A.

\section{Results}

\section{Data collection}

Normality test of data using Shapiro-Wilk test was used, that reflect the data was normally distributed after removal outliers that detected by box and whiskers plots. Additionally, testing for the homogeneity of variance revealed that there was no significant difference $(\mathrm{P}>0.05)$. All these findings allowed the researchers to conducted parametric and non-parametric analysis. Therefore, in the current study the data is parametric and normally distributed.

\section{Demographic data}

The mean values of age in group A and group B were $45.11 \pm 3.03$ and $45.10 \pm 3.77$ year, respectively. The mean values of weight in group A and group B were $82.20 \pm 6.90$ and $81.33 \pm 7.005 \mathrm{~kg}$, respectively. The mean values of height in group A and group B were $169.64 \pm 3.58$ and $169.43 \pm 4.48 \mathrm{~cm}$, respectively. The mean values of BMI in group A and group B were $28.56 \pm 2.97$ and $28.33 \pm 1.94 \mathrm{~kg} / \mathrm{m}^{2}$, respectively. The statistical analysis by independent $\mathrm{t}$-test revealed that no significant differences $(\mathrm{P}>0.05)$ in values of general demographic data (age, weight, height, and BMI) between both groups.

\section{Rest HR (BPM) Table (1)}

Within each group, the statistical analysis by paired $\mathrm{t}$-test revealed there were significantly decreased of rest HR (BPM) at post treatment compared to pre-treatment within group $\mathrm{A}(\mathrm{P}=0.0001 ; \mathrm{P}<0.05)$ and group $\mathrm{B}$ $(\mathrm{P}=0.0001 ; \mathrm{P}<0.05)$. Between both groups, the statistical analysis by independent $t$-test revealed that there were no significant difference in pre-rest $\mathrm{HR}(\mathrm{P}=0.479$; $\mathrm{P}>0.05)$ while, a significant difference in post-rest HR $(\mathrm{P}=0.0001 ; \mathrm{P}<0.05)$ between both groups.

Table (1): Comparison between mean values of pre- and post-rest HR (BPM) within each group and between both groups.

\begin{tabular}{|l|l|l|}
\hline \multirow{2}{*}{ Items } & Rest HR (BPM) & Group B \\
\cline { 2 - 3 } & Group A & $78.22 \pm 3.65$ \\
\hline Pre-treatment $($ Mean \pm SD) & $76.92 \pm 7.21$ & $74.21 \pm 0.64$ \\
\hline Post-treatment $($ Mean \pm SD) & $69.15 \pm 4.61$ & 4.01 \\
\hline Mean difference & 7.77 & $5.13 \%$ \\
\hline Improvement $\%$ & $10.10 \%$ & 4.666 \\
\hline t-value & 6.036 & 0.0001 \\
\hline P-value $(P<0.05)$ & 0.0001 & S \\
\hline Significance & S & $\begin{array}{l}\text { Post-treatment } \\
(\text { Mean } \pm \text { SD })\end{array}$ \\
\hline & $\begin{array}{l}\text { Pre-treatment } \\
(\text { Mean } \pm \text { SD) }\end{array}$ & 5.06 \\
\hline Mean difference & 1.30 & 6.524 \\
\hline t-value & 0.715 & 0.0001 \\
\hline P-value $(\mathrm{P}<0.05)$ & 0.479 & $\mathrm{~S}$ \\
\hline Significance & NS & \\
\hline
\end{tabular}

SD: standard deviation P-value: probability value NS: non-significant.

SD: standard deviation $\quad \%$ : percentage $\quad$ P-value: probability $\quad$ S: significant 


\section{Max HR (BPM) Table (2)}

Within each group, the statistical analysis by paired t-test revealed there were significantly decreased of Max HR (BPM) at post treatment compared to pre-treatment within group $\mathrm{A}(\mathrm{P}=0.0001 ; \mathrm{P}<0.05)$ and group $\mathrm{B}$
$(\mathrm{P}=0.011 ; \mathrm{P}<0.05)$. Between both groups, the statistical analysis by independent t-test revealed that there were no significant difference in pre-Max $\mathrm{HR}(\mathrm{P}=0.458$; $\mathrm{P}>0.05)$ while, a significant difference in post-Max HR $(\mathrm{P}=0.041 ; \mathrm{P}<0.05)$ between both groups.

Table (2): Comparison between mean values of pre- and post-Max HR (BPM) within each group and between both groups.

\begin{tabular}{|c|c|c|}
\hline \multirow{2}{*}{ Items } & \multicolumn{2}{|c|}{ Max HR (BPM) } \\
\hline & Group A & Group B \\
\hline Pre-treatment (Mean \pm SD) & $134.42 \pm 6.21$ & $135.47 \pm 1.08$ \\
\hline Post-treatment $($ Mean \pm SD $)$ & $128.13 \pm 10.13$ & $132.78 \pm 2.11$ \\
\hline Mean difference & 6.29 & 2.69 \\
\hline Improvement \% & $4.67 \%$ & $1.99 \%$ \\
\hline t-value & 6.829 & 3.947 \\
\hline P-value $(\mathrm{P}<0.05)$ & 0.0001 & 0.011 \\
\hline \multirow[t]{2}{*}{ Significance } & $\mathrm{S}$ & $\mathrm{S}$ \\
\hline & $\begin{array}{l}\text { Pre-treatment } \\
(\text { Mean } \pm \text { SD) }\end{array}$ & $\begin{array}{l}\text { Post-treatment } \\
(\text { Mean } \pm \text { SD) }\end{array}$ \\
\hline Mean difference & 1.05 & 4.65 \\
\hline t-value & 0.749 & 2.457 \\
\hline P-value $(\mathrm{P}<0.05)$ & 0.458 & 0.041 \\
\hline Significance & NS & $\mathrm{S}$ \\
\hline
\end{tabular}

\section{METs $\left(\mathbf{m l ~ O} \underline{Z}_{2} \underline{\mathbf{k g} / \mathbf{m i n})}\right.$ Table (3)}

Within each group, the statistical analysis by paired t-test revealed there were significantly increased of METs at post treatment compared to pre-treatment within group $\mathrm{A}(\mathrm{P}=0.002 ; \mathrm{P}<0.05)$ and group $\mathrm{B}(\mathrm{P}=0.0001 ; \mathrm{P}<0.05)$. Between both groups, the statistical analysis by independent t-test revealed that there were no significant difference in pre-METs $(\mathrm{P}=0.127 ; \mathrm{P}>0.05)$ while, a significant difference in post-METs $(\mathrm{P}=0.001 ; \mathrm{P}<0.05)$ between both groups. 
Table (3): Comparison between mean values of pre- and post-METs $\left(\mathrm{ml} \mathrm{O}_{2} / \mathrm{kg} / \mathrm{min}\right)$ within each group and between both groups.

\begin{tabular}{|c|c|c|}
\hline \multirow{2}{*}{ Items } & \multicolumn{2}{|c|}{ METs (ml O2/kg/min) } \\
\hline & Group A & Group B \\
\hline Pre-treatment $($ Mean $\pm \mathrm{SD})$ & $1.87 \pm 0.2$ & $1.94 \pm 0.8$ \\
\hline Post-treatment (Mean \pm SD) & $2.74 \pm 0.7$ & $3.20 \pm 0.5$ \\
\hline Mean difference & 0.87 & 1.26 \\
\hline Improvement \% & $64.95 \%$ & $46.52 \%$ \\
\hline t-value & 4.568 & 7.257 \\
\hline $\mathrm{P}$-value $(\mathrm{P}<0.05)$ & 0.002 & 0.0001 \\
\hline \multirow[t]{2}{*}{ Significance } & $\mathrm{S}$ & $\mathrm{S}$ \\
\hline & $\begin{array}{l}\text { Pre-treatment } \\
(\text { Mean } \pm \mathrm{SD})\end{array}$ & $\begin{array}{l}\text { Post-treatment } \\
(\text { Mean } \pm \text { SD) }\end{array}$ \\
\hline Mean difference & 0.07 & 0.46 \\
\hline t-value & 1.568 & 14.740 \\
\hline $\mathrm{P}$-value $(\mathrm{P}<0.05)$ & 0.127 & 0.001 \\
\hline Significance & NS & $\mathrm{S}$ \\
\hline
\end{tabular}

\section{Max SBP (mm Hg) Table (4)}

Within each group, the statistical analysis by paired t-test revealed there were significantly decreased of Max $\mathrm{SBP}$ at post treatment compared to pre-treatment within group $\mathrm{A}(\mathrm{P}=0.0001 ; \mathrm{P}<0.05)$ and group $\mathrm{B}(\mathrm{P}=0.039 ; \mathrm{P}<0.05)$. Between both groups, the statistical analysis by independent t-test revealed that there were no significant difference in pre-Max SBP $(\mathrm{P}=0.878 ; \mathrm{P}>0.05)$ while, a significant difference in post-Max $\mathrm{SBP}(\mathrm{P}=0.006 ; \mathrm{P}<0.05)$ between both groups.

Table (4): Comparison between mean values of pre- and post-Max SBP (mm Hg)within each group and between both groups.

\begin{tabular}{|l|l|l|}
\hline \multirow{2}{*}{ Items } & Max SBP $(\mathbf{m m} \mathbf{H g})$ & \multicolumn{2}{|l|}{} \\
\cline { 2 - 3 } & Group A & $135.00 \pm 10.95$ \\
\hline Pre-treatment (Mean \pm SD) & $136.00 \pm 0.51$ & $131.96 \pm 5.88$ \\
\hline Post-treatment (Mean \pm SD) & $129.95 \pm 0.64$ & 3.04 \\
\hline Mean difference & 6.05 & $2.25 \%$ \\
\hline Improvement \% & $4.45 \%$ & 2.177 \\
\hline t-value & 5.047 & 0.039 \\
\hline P-value $(\mathrm{P}<0.05)$ & 0.0001 & B \\
\hline
\end{tabular}


Cont... Table (4): Comparison between mean values of pre- and post-Max SBP (mm Hg)within each group and between both groups.

\begin{tabular}{|l|l|l|}
\hline Significance & S & S \\
\hline & $\begin{array}{l}\text { Pre-treatment } \\
(\text { Mean } \pm \text { SD })\end{array}$ & $\begin{array}{l}\text { Post-treatment } \\
\text { (Mean } \pm \text { SD })\end{array}$ \\
\hline Mean difference & 1.00 & 2.01 \\
\hline t-value & 0.878 & 3.764 \\
\hline P-value $(P<0.05)$ & 0.359 & 0.006 \\
\hline Significance & NS & S \\
\hline
\end{tabular}

\section{Max DBP (mm Hg) Table (5)}

Within each group, the statistical analysis by paired t-test revealed there were significantly decreased of Max DBP at post treatment compared to pre-treatment within group $\mathrm{A}(\mathrm{P}=0.0001 ; \mathrm{P}<0.05)$ and group $\mathrm{B}(\mathrm{P}=0.006$; $\mathrm{P}<0.05)$. Between both groups, the statistical analysis by independent $t$-test revealed that there were no significant difference in pre-Max DBP $(\mathrm{P}=0.764 ; \mathrm{P}>0.05)$ while, a significant difference in post-Max $\mathrm{DBP}(\mathrm{P}=0.012 ; \mathrm{P}<0.05)$ between both groups.

Table (5): Comparison between mean values of pre- and post-Max DBP ( $\mathrm{mm} \mathrm{Hg}$ ) within each group and between both groups.

\begin{tabular}{|c|c|c|}
\hline \multirow{2}{*}{ Items } & \multicolumn{2}{|c|}{ Max DBP (mm Hg) } \\
\hline & Group A & Group B \\
\hline Pre-treatment $($ Mean \pm SD) & $85.01 \pm 13.20$ & $85.99 \pm 5.83$ \\
\hline Post-treatment (Mean $\pm \mathrm{SD})$ & $76.98 \pm 10.99$ & $80.00 \pm 9.40$ \\
\hline Mean difference & 8.03 & 5.99 \\
\hline Improvement \% & $9.45 \%$ & $6.97 \%$ \\
\hline t-value & 10.816 & 3.078 \\
\hline $\mathrm{P}$-value $(\mathrm{P}<0.05)$ & 0.0001 & 0.006 \\
\hline \multirow[t]{2}{*}{ Significance } & S & S \\
\hline & $\begin{array}{l}\text { Pre-treatment } \\
(\text { Mean } \pm \text { SD) }\end{array}$ & $\begin{array}{l}\text { Post-treatment } \\
(\text { Mean } \pm \text { SD) }\end{array}$ \\
\hline Mean difference & 0.98 & 3.02 \\
\hline t-value & 0.302 & 2.478 \\
\hline $\mathrm{P}$-value $(\mathrm{P}<0.05)$ & 0.764 & 0.012 \\
\hline Significance & NS & $\mathrm{S}$ \\
\hline
\end{tabular}


7. VO $2 \underline{2} \underline{\operatorname{Max}(\mathrm{ml} / \mathrm{kg} / \mathrm{min})}$ Table (6)

Within each group, the statistical analysis by paired t-test revealed there were significantly increased of $\mathrm{VO}_{2}$ at post treatment compared to pre-treatment within group $\mathrm{A}(\mathrm{P}=0.0001 ; \mathrm{P}<0.05)$ and group $\mathrm{B}(\mathrm{P}=0.008 ; \mathrm{P}<0.05)$. Between both groups, the statistical analysis by independent t-test revealed that there were no significant difference in pre- $\mathrm{VO}_{2}(\mathrm{P}=0.478 ; \mathrm{P}>0.05)$ while, a significant difference in post- $\mathrm{VO}_{2}(\mathrm{P}=0.018 ; \mathrm{P}<0.05)$ between both groups.

Table (6): Comparison between mean values of pre- and post- $\mathrm{VO}_{2} \mathrm{Max}(\mathrm{ml} / \mathrm{kg} / \mathrm{min})$ within each group and between both groups.

\begin{tabular}{|c|c|c|}
\hline \multirow{2}{*}{ Items } & \multicolumn{2}{|c|}{ VO2 Max (ml/kg/min) } \\
\hline & Group A & Group B \\
\hline Pre-treatment (Mean \pm SD) & $31.02 \pm 2.78$ & $31.99 \pm 5.46$ \\
\hline Post-treatment $($ Mean \pm SD) & $41.99 \pm 6.58$ & $37.00 \pm 11.42$ \\
\hline Mean difference & 10.97 & 5.01 \\
\hline Improvement \% & $35.36 \%$ & $15.66 \%$ \\
\hline t-value & 7.887 & 2.977 \\
\hline $\mathrm{P}$-value $(\mathrm{P}<0.05)$ & 0.0001 & 0.008 \\
\hline \multirow[t]{2}{*}{ Significance } & $\mathrm{S}$ & $\mathrm{S}$ \\
\hline & $\begin{array}{l}\text { Pre-treatment } \\
(\text { Mean } \pm \mathrm{SD})\end{array}$ & $\begin{array}{l}\text { Post-treatment } \\
(\text { Mean } \pm \mathrm{SD})\end{array}$ \\
\hline Mean difference & 0.97 & 4.99 \\
\hline t-value & 0.717 & 2.355 \\
\hline P-value $(\mathrm{P}<0.05)$ & 0.478 & 0.018 \\
\hline Significance & NS & $\mathrm{S}$ \\
\hline
\end{tabular}

Ethical Clearance: Approval of the ethical committee of the faculty of physical therapy of Cairo University (No:P.T.REC/012/002148), written consent prior participation and confidentiality was assured.

Source of Funding: Self

\section{Conflict of Interest: Nil}

\section{Discussion}

The main aim of this study was to determine if there was any difference in effect of aerobic training on selected cardiopulmonary parameters in myocardial infarction patients with stroke.

Patients in cardiac rehabilitation are typically advised to complete a period of supervised aerobic training, in the current study there was significant difference in systolic and diastolic blood pressure in addition to heart rate with privilege to group A whom received aerobic exercise training.

This was explained by Kjeldsen et al (5), who proved that SBP and DBP rise during exercise provides information about the hemodynamic response to increasing physical stress. Dynamic exercise produces 
a large increase in SBP and DBP. The highest cardiovascular disease mortality rate was observed in men with both elevated resting and exercise blood pressure. They reported that SBP and DBP at moderate and peak workloads was directly associated with the risk of cardiovascular events in hypertensive men with an increased risk of any stroke.

Both SBP and DBP changed to levels that were statistically significant when comparing both groups after the program, although changes in both groups separately were not significant. Percent of change in SBP was (4.2 $\% \downarrow$ and $2.1 \% \uparrow)$ and DBP was $(2.6 \% \downarrow$ and $2.3 \% \uparrow)$ for study and control groups respectively. Improvement of study group and deterioration of control group showed the positive effect of Cardiac Rehabilitation program ${ }^{(6)}$.

In the current study there was significant improvement in METs with aerobic training which was approved by Swain and Franklin (7), they demonstrated on their study improvements were 1.41 METs (39\% improvement), 1.01 METs (15\% improvement), and 0.80 MET (8.6\% improvement) for the low, moderate, and high cardiorespiratory fitness patients (at baseline), respectively. The greatest improvements occurred in those patients who were most likely to benefit most from an aerobic training intervention, that is, those in the lowest cardiorespiratory fitness, high-risk cohort.

The present study showed significant improvement $\mathrm{VO}_{2}$ max outcome after aerobic training, the result goes with a study in individuals starting exercise within 6 days to 6 months after stroke onset, revealed a large effect size. This finding supports the evidence that individuals in the sub-acute stage after stroke have high potential to increase $\mathrm{VO}_{2}$ peak following a cardiovascular training intervention. This is in addition to a spontaneous recovery of peak aerobic capacity of $16.9 \%$ that occurs during the first 6 months after stroke. But given the fact that $\mathrm{VO}_{2}$ peak is reduced within 0-30 days after stroke, and $10 \mathrm{ml} / \mathrm{kg} / \mathrm{min}$ is required for light activities of daily living (ADL), this small improvement of peak aerobic capacity could lead to a large functional carryover ${ }^{(\mathbf{8})}$.

\section{Conclusion}

The results of this study revealed better improvement of aerobic exercise more than those of traditional physical therapy program alone. Aerobic exercise could be considered a valuable method for improvement of cardiopulmonary parameters on myocardial infarction patients with stroke.

\section{References}

1. Borja I, Stefan J, Stefan A, Manuel J and Petr W. The Task Force for the management of acute myocardial infarction in patients presenting with ST-segment elevation of the European Society of Cardiology, European Heart Journal, 2020, Volume 39, Issue 2, Pages 119-177.

2. Oliver S, Eling D, Ruud H s, and Kenneth J. Effects of cardiovascular exercise early after stroke: systematic review and meta-analysis, BMC Neurol, 2016, 12: 45.

3. Gerald F., Philip A. and Kligfield P.: Exercise Standards for Testing and Training a Scientific Statement from the American Heart Association. Circulation, 2016, 128: 873-934.

4. Harsh P, Hassan A, Raef M, Niel S, and Timothy J. Aerobic vs anaerobic exercise training effects on the cardiovascular system. World J Cardiol, 2017, 26; 9(2): 134-138.

5. Kjeldsen SE, Mundal R, Sandvik L, Erikssen $G$ and Erikssen J. Exercise blood pressure predicts cardiovascular death and myocardial infarction. Blood Press Monit, 2017, 2: 147-153.

6. Hassan AM and El Nahas NG. Efficacy Of Cardiac Rehabilitation After Percutaneous Coronary Intervention. International Journal of PharmTech Research, 2016, Vol.9, No.4, pp 134-141.

7. Swain DP and Franklin BA. Comparison of cardioprotective benefits of vigorous versus moderate intensity aerobic exercise. Am J Cardiol, 2016, 97(1):141-147.

8. MacKay-Lyons MJ and Makrides L. Longitudinal changes in exercise capacity after stroke. Archives of Physical Medicine and Rehabilitation, 2014, 85(10):1608-1612. 